\title{
THE OBJECT OF LOVE IS FOOD Conceptual Metaphor in Selected Dholuo Benga Music of 1970s and 2000s
}

\author{
Lydia Akuno, Pamela Anyango Oloo, Magonya Achieng' Lilian* \\ Department of Linguistics, Languages and Literature, Maseno University, Kenya
}

Copyright $\bigcirc 2018$ by authors, all rights reserved. Authors agree that this article remains permanently open access under the terms of the Creative Commons Attribution License 4.0 International License

\begin{abstract}
One of the ways in which people express their emotions creatively in a society is through music. Benga music is a genre of Kenyan popular music that has been in existence from 1960s to date. Over the years, Dholuo benga music has seen artistes of 1970s like Ochieng Kabaselleh, Kasongo, Owino Misiani, and many others, giving way to more recent Dholuo benga artistes of the year 2000s like Atomi Sifa, Madanji Perimeter and Otieno Aloka. Dholuo is a Nilotic language spoken along the shores of Lake Victoria, Kenya. Aspects of language, like metaphorical expressions, usually vary over time due to external and internal influences on a speech community. Variations may also occur depending on different individuals' conceptualizations of emotions. Dholuo benga love songs are characterized by metaphorical expressions of love which are evidence of conceptual metaphors of love as perceived by Dholuo benga artistes over the decades. The aim of this comparative study was to establish similarities and variations in conceptualization of OBJECT OF LOVE AS FOOD by two male Dholuo benga artistes in Kenya, in two different time frames (1970s and 2000s). The study therefore hoped to explain language use in Dholuo benga love songs over time. The study was guided by Lakoff and Johnson (1980) Conceptual Metaphor Theory. The study population comprised a total of ten Dholuo benga love songs. Thirteen metaphoric expressions of love were extracted from lyrics of the ten love songs by Ochieng Kabaselleh and Atomi Sifa. Purposive sampling technique was used to select the love songs with required metaphorical expressions and saturated sampling technique was employed to get the requisite linguistic metaphors of love. The study findings are that there exist similarities and variations in the conceptualization of OBJECT OF LOVE IS FOOD between the 1970s and 2000s male Dholuo benga artistes.
\end{abstract}

Keywords Metaphor, Love, Cross-domain Mappings

\section{Introduction}

A conceptual metaphor is defined as the systematic structuring or restructuring of one conceptual target domain in terms of a source domain through the projection of semantic features of one domain on to the other. Typically, target domains are abstract while source domains are concrete. In other words, a conceptual metaphor is defined as understanding a more abstract conceptual domain in terms of a less abstract and a more concrete domain by using knowledge structures of a less abstract aspect of experience to reason about a more abstract aspect of experience Kövecses [1]. Conceptual metaphors are abstract and are realized in language by linguistic metaphors. Lakoff and Johnson [2] therefore propose that linguistic metaphors serve as evidence of the embodied nature of our conceptual organization. Taking the LOVE IS A JOURNEY conceptual metaphor as an illustration, Lakoff and Johnson [2] perceive the structure of journeys used to metaphorically understand the target domain of love in English. The following cross- domain mappings explain the metaphorical expressions.

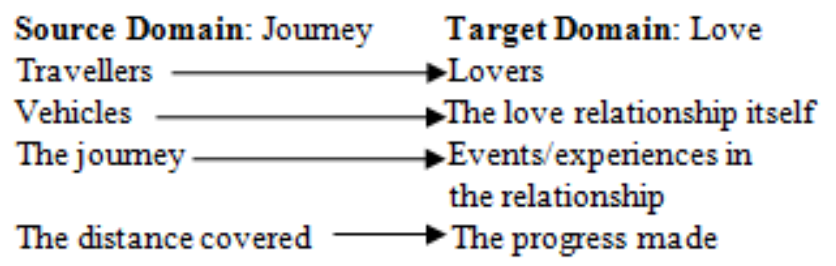

Figure1. Cross domain mappings of LOVE IS A JOURNEY

Travellers are mapped onto lovers, vehicles on to the love relationship itself, the journey onto events or experiences in the relationship and the distance covered onto the progress made in the relationship. From these mappings, one thus gets linguistic metaphors such as, Look how far we've come, We've hit a dead-end street, We can't turn back now and so on Lakoff \& Johnson, [2] 
Aspects of language, just like other aspects of culture, tend to change over time. More often than not, the needs of speakers like new technologies, products and experiences require new words which all drive language change. It is also worth noting that no two individuals use language in exactly the same way. The vocabulary and phrases people use depend on where they live, their age, education level and social status Butler, [3]. Kövecses [4] addresses causes of metaphor variation and points out that metaphor may vary along social, style, sub-cultural and individual dimensions. Kövecses [4] explains that many metaphors vary because of variations in human experiences. At the same time, metaphors vary because the diverse cognitive processes we put to use for the creation of abstract thought may also vary. Lakoff and Johnson [2] argue that human communication is intrinsically metaphorical, and that human communication as we know it could not exist without metaphor. They add that our most essential mental concepts like time and space are inherently suffused with metaphorical descriptions, so that "The way we think, what we experience and what we do every day is very much a matter of metaphor" Lakoff \& Johnson [2]. The concept of love is perhaps the most highly 'metaphorized' emotion concept as observed by Kövecses [5]. He says that this is possibly due to the fact that it is not only an emotion, but a relationship as well. Lakoff and Johnson [2] quoted by Kövecses (2000) studied conceptual metaphors for love and they point out that conceptual metaphors for love which make themselves manifest in every language use are as follows:

LOVE IS A NUTRIENT: I am starved for love.

LOVE IS A JOURNEY: It's been a long bumpy road.

LOVE IS A BOND: There is a close tie between them.

LOVE IS A FLUID IN A CONTAINER: She was over

flowing with love.

LOVE IS FIRE: I am burning with love.

LOVE IS A NATURAL FORCE: She swept me off my

feet.

LOVE IS WAR: She conquered him.

LOVE IS INSANITY: I am crazy about you.

THE OBJECT OF LOVE IS AN APPETIZING

FOOD: Hi, sweetie-pie.
THE OBJECT OF LOVE IS A SMALL CHILD: Well, baby, what are we gonna do?

THE OBJECT OF LOVE IS A VALUABLE OBJECT: You're my treasure (adapted from Kövecses, [5].

For the purpose of this study, we examine OBJECT OF LOVE IS FOOD conceptual metaphor which is a variant of WOMAN AS DESSERT conceptual metaphor by Hines [6]. Hines notes that WOMEN ARE SWEET OBJECTS and the sweetness is metaphorical referring to their supposed sweet nature rather than an actual flavour. Hines explains that the dessert metaphor, however, goes further implicitly trivializing women, reducing them to their sexuality and then equating them with not just any edible food but specifically peripheral food items. As desserts, women can be bought and sold; eaten, elaborately decorated and admired for their outward appearance. They can also be dismissed as sinful and decadent or in the ultimate degradation, simply done without just like desserts are optional and frivolous. Hines further notes that people metaphorically and unconsciously relate sex to food which has given rise to gender related terms. Just like the present study and Kövecses [5], Hines notes that there are endearment terms such as sweetheart, honey, sugar and sweetie pie used by lovers. Hines concludes that actually a large number of slang terms used in reference to women and their genitalia, for example, pudding, jelly bag, honey pot, melons, strawberries and the like, draw upon the dessert metaphor. Hines describes the evolution of the WOMEN AS DESSERT metaphor in Figure 2. She points out that it begins with the PEOPLE ARE OBJECTS metaphor, an example of which in the special case Lakoff and Johnson [2] have called PEOPLE ARE BUILDINGS, as in Eyes are windows to the soul. Hines adds that this ungendered metaphor has common aspects with a cultural stereotype such as women are sweet and with another common metaphor ACHIEVING A DESIRED OBJECT IS GETTING SOMETHING TO EAT as in, She tasted victory. Hines finally remarks that women are consequently viewed as sweet objects, in this case, desserts as conceptualized by Hines 1994 [6].

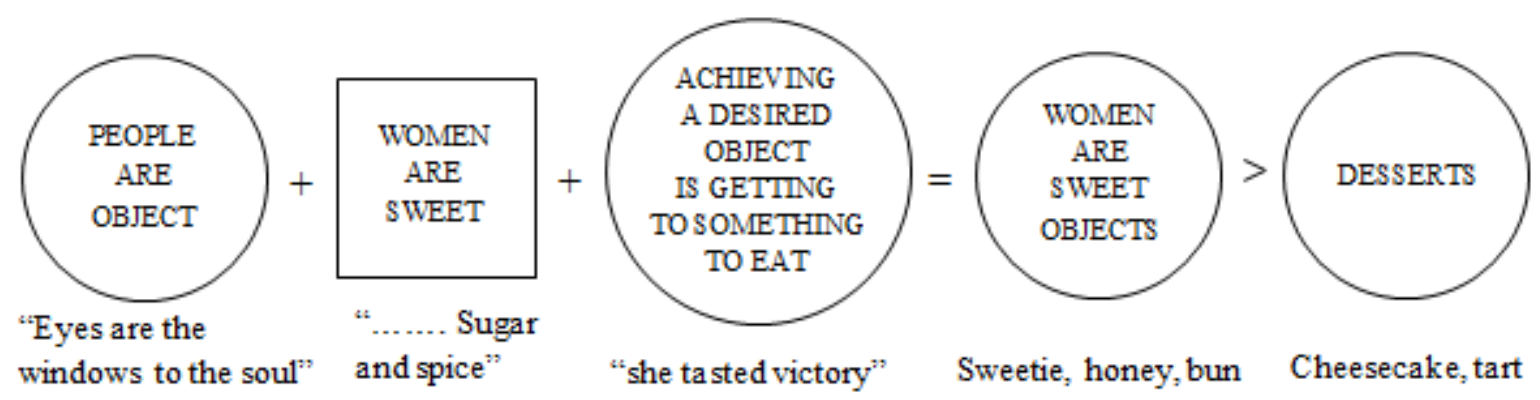

Figure 2. Evolution of the WOMAN AS DESSERT Metaphor 
The WOMAN AS DESSERT metaphor together with other love metaphors will be examined in this study, which is a comparative analysis of LOVE IS FOOD conceptual metaphor in selected Dholuo benga love songs of the years 1970s and 2000s by Ochieng Kabaselleh and Atomi Sifa respectively. Benga is a genre of Kenyan popular music. This study notes that Benga music is dynamic and has developed over the years from 1960s to date Daily Nation, Friday, [7]. This study is aimed at establishing the metaphorical variations in the OBJECT OF LOVE IS FOOD conceptual metaphor between 1970s and 2000s male Luo benga artistes.

\section{Statement of the Problem}

One of the ways by which people communicate in a society is through songs. Recorded Dholuo benga songs have been in existence since the 1960s. Different aspects of culture including language aspects usually vary over time due to external and internal influences on a speech community. Variations in linguistic features like metaphorical expressions may also occur depending on individuals' conceptualization of emotions. Over the years, Dholuo benga music has seen benga artistes of 1970s like Ochieng Kabaselleh, Kasongo, Owino Misiani, and many others giving way to more recent Dholuo benga artistes of the year 2000s like Atomi Sifa, Madanji Perimeter and Otieno Aloka. The themes that these two groups of artistes address such as love, politics and social relationships, however, remain unchanged even though their songs sound quite different. Both Ochieng Kabaselleh (1970s) and Atomi Sifa (2000s) have addressed the conceptual metaphor OBJECT OF LOVE IS FOOD metaphor in their songs. But given the time frame in the period that the songs were sang and the variations that occur in language use over time, Kabaselleh's and Atomi's conceptualization of OBJECT OF LOVE IS FOOD metaphor could explain language use in the lyrics of their love songs. This study therefore seeks to identify the linguistic metaphors that motivate OBJECT OF LOVE IS FOOD by Ochieng Kabaselleh and Atomi Sifa. The identification of the linguistic metaphors by the two artistes is to aid in establishing whether Ochieng Kabaselleh and Atomi Sifa have the same or different conceptualization of OBJECT OF LOVE IS FOOD.

\section{Objective of the Study}

The objective of the study was to establish the metaphorical similarities and variations in the OBJECT OF LOVE IS FOOD conceptual metaphor between 1970s and 2000s male Luo benga artistes. This was to help explain the choice of words used in reference to the loved ones by the two benga artistes in the love songs.

\section{Theoretical Framework}

This study was premised on the Conceptual Metaphor Theory, also sometimes called Cognitive Metaphor Theory. The theory was primarily developed by George Lakoff within the field of Cognitive Linguistics. The main proponents of the conceptual metaphor theory are George Lakoff and Mark Johnson [2].Based on Lakoff and Johnson [2], Deignan [8] says that conceptual metaphor theory (C.M.T.) is essentially a theory about cognition that analyses patterns of figurative language. The theory's tenets are as follows: metaphors structure thought, metaphors structure knowledge, metaphor is central to abstract language, metaphor is grounded to physical experience and metaphor is ideological Deignan [8].

Within the C.M.T., Lakoff and Johnson [2] differentiate between three main kinds of metaphors, namely; structural, orientational and ontological metaphors. Structural metaphors are instances where one metaphorically structures one concept in terms of another. This phenomenon is exemplified with the ARGUMENT IS WAR conceptual metaphor. In this example, the concept of ARGUMENT is metaphorically structured in the concept of WAR. This conceptual metaphor is realized in language by expressions such as, He shot down all my arguments, and He lost or won the argument Lakoff \& Johnson [2].

Orientational metaphors are more extensive than the structural ones. In that, they organize a whole system of concepts with respect to one another. These kinds of metaphors have to do with spatial orientation, such as up down and in - out. The orientations arise from our embodied experience with our physical environment for example HAPPY IS UP which is realized in linguistic metaphor like 'I'm feeling up' and accordingly, there is also a conceptual metaphor with the opposite meaning namely; SAD IS DOWN realized in linguistic expressions like 'I'm feeling low' Lakoff \& Johnson[2].

The third type of metaphor is the ontological metaphor. This is said to be the most basic kind when it comes to comprehending and understanding our experience. Ontological metaphors are about understanding our experiences in terms of entities and substances which means we can refer to them, quantify them, categorize them, and reason about them in ways otherwise impossible Lakoff \& Johnson [2] These metaphors are realized when we impose boundaries marking off a territory so that it has an inside and a bounding surface, for example, woods, which enables us to use expressions such as "He went into the woods" Lakoff \& Johnson [2]. A clearing in the woods is seen as having a bounding surface and we can view ourselves as being in the clearing or out of the clearing, in the woods or out of the woods. Even in the case where there is no natural physical boundary that can be viewed as defining a container, some experiences and objects around us are easily treated as entities or substances. We impose imagined boundaries on things that are not physical such as 
the mind. A case in point is the THE MIND IS A CONTAINER metaphor which is realized in metaphoric expressions like 'my mind is full.'

\section{Methodology}

The study adopted analytical research design to analyze the linguistic metaphors that motivate the OBJECT OF LOVE IS FOOD conceptual metaphor in Dholuo benga songs by Kabaselleh and Atomi. Kabaselle compared to other benga artistes of 1970s had addressed the theme of love in many of his songs and the same applied to Atomi Sifa whose songs were mainly love songs among other benga artistes of 2000s. The study population comprised ten love songs out of which five were by Ochieng' Kabaselleh and five by Atomi Sifa. There were a total of thirteen metaphoric expressions extracted from the ten songs, seven by Atomi Sifa and six by Ochieng Kabaselleh. The study employed purposive sampling to sample the relevant love songs and metaphoric expressions while saturated sampling method was used to get the thirteen metaphoric expressions. Data collection technique was corpus compilation method. The researcher in this case, personally listened to audio-tape recordings of benga love songs and then extracted, transcribed and compiled metaphoric expressions motivated by OBJECT OF LOVE IS TASTY FOOD conceptual metaphor. The metaphoric expressions were then translated into English.

\section{Discussion}

Dholuo benga love music by both Atomi Sifa and Ochieng Kabaselleh indicate evidence of THE OBJECT OF LOVE IS FOOD conceptual metaphor as shown in Tables 1 and 2.

Table 1.Expressions by Atomi Sifa

\begin{tabular}{|c|c|}
\hline Metaphoric Expressions of Love & Song Title \\
\hline M.1 Emma switina. & Emma (2003) \\
\hline (Emma my sweet) & Emma (2003) \\
\hline $\begin{array}{l}\text { M.2 Maziwa mara e siti. } \\
\text { (My milk in the city) }\end{array}$ & \\
\hline $\begin{array}{l}\text { M.3 Lav yako kama asali. } \\
\text { (Your love is like honey) }\end{array}$ & Oyiengo nyar maro (2007) \\
\hline $\begin{array}{l}\text { M.4 Adori Big ' } \boldsymbol{G} \text { ' } \\
\text { (Adori Big 'G') }\end{array}$ & Adori Big ' $G$ '(2002) \\
\hline $\begin{array}{c}\text { M.5 Sella Patco } \\
\text { (Sella patco sweets) }\end{array}$ & Sella Patco (2006) \\
\hline $\begin{array}{l}\text { M.6 Baby patco ber nyodho. } \\
\text { (It is nice sucking baby patco) }\end{array}$ & Sella patco (2006) \\
\hline $\begin{array}{l}\text { M.7 Adhiambo omboga mawendo, ithole, } \\
\text { ikuoge iole chak. }\end{array}$ & Adhiambo Omboga Mawendo \\
\hline $\begin{array}{l}\text { (Adhiambo is foreign vegetable that is } \\
\text { roasted, fermented and added milk) }\end{array}$ & \\
\hline
\end{tabular}

Note: M. stands for metaphorical expressions

The OBJECT OF LOVE IS FOOD conceptual metaphor which is a structural metaphor has two domains Lakoff \& Johnson, [2]; the target domain is 'object of love' while the source domain is 'food'. Love which is the target domain, is an abstract emotional feeling in that it can neither be seen nor touched, but somehow whatever an individual who is in love feels has been likened to the feeling that one gets when eating food. Eating food is an everyday physical experience that everybody is able to comprehend. The two artistes have, in this case, attempted to describe love in terms of a concrete object (food) which is the source domain. On analyzing the tenets of conceptual metaphor theory, Deignan [8] too explains that metaphor is grounded to physical experience, in this instance the experience of eating foods like sugar, sweets, chewing gum, honey, milk, roasted groundnuts and specially prepared traditional vegetables.

Table 2. Expressions by Ochieng Kabaselleh

\begin{tabular}{|c|c|}
\hline Metaphoric Expressions of Love & Song Title \\
\hline $\begin{array}{c}\text { M.8 } \text { Imiya herani duto inbe amiyi duto hani. } \\
\text { (You give me your love and I too will give you } \\
\text { my love, my honey) }\end{array}$ & Nya seje (1975) \\
M.9 Anyango parie herawa switi. & Wang 'luangni (1975) \\
(Anyango please remember our love sweety) & \\
M.10Maziwa yangu baby. & Maziwa na (1975) \\
(Baby you are my milk) & Maziwa na (1975) \\
M.11 Hani Adundo switi. & \\
(The short one you are my honey, sweety) \\
M.12 Njugu Karanga Adhiambo nya Alego \\
(Adhiambo from Alego is roasted groundnuts) \\
M.13 Nikech hera maherigo sukarina \\
(Because of my love for you my sugar)
\end{tabular}

\subsection{THE OBJECT OF LOVE IS A SWEET}

The two artistes liken love to 'sweets' albeit with slight variations as shown in M.1, M.9 and M.11. In M.1 Atomi refers to his loved one as Emma switina meaning 'Emma my sweet.'Ochieng Kabaselleh too uses the expression 'sweet' to refer to his loved one in M.9 where he says Anyango parie herawa switi which means 'Anyango sweety remember our love.' And in M.11 again he talks of Honey Adundo switi, which is also a reference to the loved one as 'a sweet'. Sweets are generally sugary and popular especially among children and one would enjoy the feeling that is got from the sucking. These metaphoric expressions are evidence of OBJECT OF LOVE IS A SWEET conceptual metaphor.

Atomi Sifa, unlike Kabaselleh goes ahead to specify the types of sweets that he likes. This is seen as an aspect of metaphoric idiosyncratic variations between the two artistes. For example, in M.5 he singles out Patco sweets when he says Sella Patco. Patco sweets are types of sweets that are easily found in local shops; they are cheap, colourful, easily dissolve in saliva and are very sugary. Atomi Sifa may have picked on Patco sweets because of their popularity especially in the rural areas like where he grew up or just because he specifically loves Patco more 
than other sweets. Atomi therefore conceptualizes THE OBJECT OF LOVE IS A PATCO SWEET metaphor. In M.4, Atomi talks of Adori Big G. Big G are a popular brand of chewing gum that has been in existence for quite a while. It is pink in colour, very soft to chew and just like Patco sweets, it is very sugary. Again, Atomi could have singled out Big $\mathrm{G}$ among other chewing gums because he is more familiar with them or loves them more or maybe it could just be his unique linguistic style Kövecses, [4], giving rise to THE OBJECT OF LOVE IS A BIG G conceptual metaphor. The love that the artistes have for sweets and the sweet experience they get from sweets influence their perception on the love that they feel for the women they love, thus ending up referring to the lovers as sweets. This could mean that according to the artistes the feeling of love is as sweet as the taste of sweets.

\subsection{THE OBJECT OF LOVE IS SUGARY FOODS}

Similarly, in M.13 object of love is viewed as sugar by Ochieng Kabaselleh. He says Nikech hera maherigo sukarina, translated as 'Because of the love I have for you my sugar.' Sugar is a sweetener used in drinks and other sugary foods like cakes, chocolates and the like. Sugar is a commodity that is used both domestically and industrially because of its sweetness. And just like other foods that the benga artistes have perceived as objects of love, sugar is a locally available commodity but relatively costly to the common man making it a treasure to many. Sugar gives a sweet flavour when licked or added to other foods the same way sweets and chewing gums do, hence THE OBJECT OF LOVE IS SUGAR. This notion also exists in English which has the metaphoric expression having a sweet tooth to denote love for sugary things.

Another sugary food identified by the research is honey. Honey has been used in reference to objects of love for example, in M.3 Atomi Sifa remarks Lav yako kama asali. This is an expression in Kiswahili meaning 'Your love is like honey.' This is a simile that compares the sweetness of love to that of honey. Ochieng Kabaselleh shares in the perception in M.8 where he says Imiya herani duto inbe amiyi hera hani, meaning 'Give me all your love and I also give you my love honey' The same expression is used in M.11 Hani Adundo switi, which can be translated as 'The short one, my honey and sweet.' In such metaphoric expressions, Kabaselleh is directly calling his loved one honey. Honey is known for its very tasty flavour and nutritional value. In everyday speech there are common similes that are often used in relation to the tasty flavour of honey; for example in English there exists a simile '...as sweet as honey.' Likewise, Kiswahili too has the expression '...tamu kama asali.' Bee keeping is not a popular activity among the Luo whose economic activities are majorly crop farming, animal keeping and fishing. Because of this, honey is not food that can be found in every home as the process of obtaining it is also very tedious and costly so whoever gets honey treasures it. One can then conclude that the Dholuo benga artistes have gone ahead to look at women they love as 'honey' because of its tasty flavor and rarity, making it extremely precious. From the above metaphoric expressions, the research is able to identify the THE OBJECT OF LOVE IS HONEY conceptual metaphor as perceived by the two benga artistes.

\subsection{THE OBJECT OF LOVE IS A SWEET DRINK}

Other than sugary food, milk has also been likened to women who are objects of love. In M.2 Atomi Sifa says Maziwa mara e siti to mean 'The loved one is my milk in the city.' Ochieng Kabaselleh also uses the same expression in M.10 when he says Maziwa yangu bebi, which is a Kiswahili reference to his loved one as milk. The two benga artistes have perceived milk as tasty and cherished food. Milk is valued by many Kenyan communities like the Kalenjins who consider it a delicacy. Other than the Kalenjins (a Nilotic ethnic group inhabiting the Rift Valley in Kenya), the Luos too value milk and used it to supplement the less delicious dishes like vegetables. Milk could also be taken as a main meal served with starches like ugali or sweet potatoes. In this case, the milk would be fermented for days in a special guard known as Koo to give it a sour taste. Ghee which is also a milk product equally valued by the Luos, is prepared through the same process of fermentation. Ghee is then used as a spice to enrich traditional vegetables and other delicacies like smoked fish. Okumba [9] on Luo cuisines observes that the standard diet of Luos consists of ugali and stews; the stews are often lavishly embellished with milk, ghee and simsim paste which makes them very tasty. Other than the tasty flavour, milk is also very nutritious making it a recommendation for the children's diet. Milk though locally available, not everybody can afford to take it regularly because of the cost involved. The fact that milk is not readily available for every other person, could also explain why both Atomi Sifa and Ochieng Kabaselleh treasure it and can only compare it to their loved one, hence the OBJECT OF LOVE IS MILK conceptual metaphor.

\subsection{THE OBJECT OF LOVE IS A DELICIOUS VEGETABLE}

The comparison of object of love to food is also found in M.7 where Atomi Sifa calls his loved one Omboga mawendo meaning rare vegetables though literally translated would mean 'A visiting vegetable.' According to him, this is a very tasty and rare delicacy that he adores unlike the ordinary vegetables. Vegetables is a dish that many people do not value but traditionally, Luos have a way of making the traditional vegetables more palatable by preserving it for a period of time by constantly warming it with addition of milk and ghee only as was pointed out by 
Okumba [9]. The process of preparing this vegetable is long and tedious as Atomi talks of ithole, ikuoge, iole chak in M.7 translated as 'It is roasted, fermented and maintained with milk.' The end result is usually a very tasty vegetable commonly known as alot mokwogi in Dholuo. In the mind of Atomi Sifa eating omboga mawendo is comparable to the feeling he experiences with his loved one.

\subsection{THE OBJECT OF LOVE IS A DELICIOUS SNACK}

Ochieng Kabaselleh likewise refers to the woman he loves in M.12 Njugu Karanga which is a Kiswahili term for roasted groundnuts. This too is an appetizing food popular among the Luo give that their economic life revolves around subsistence farming which includes growing of groundnuts, sorghum among other crops. Roasted groundnuts is a tasty, crunchy and nutritious delicacy which can be served with beverage for breakfast and can also be taken as a pastime snack both at home and in social places. It is therefore food of value and popular among the Luos. These qualities could explain why Ochieng Kabaselleh likens the love he has for his loved one to that of roasted groundnuts.

The mappings of the conceptual metaphor can be summarized as in Figure 3:

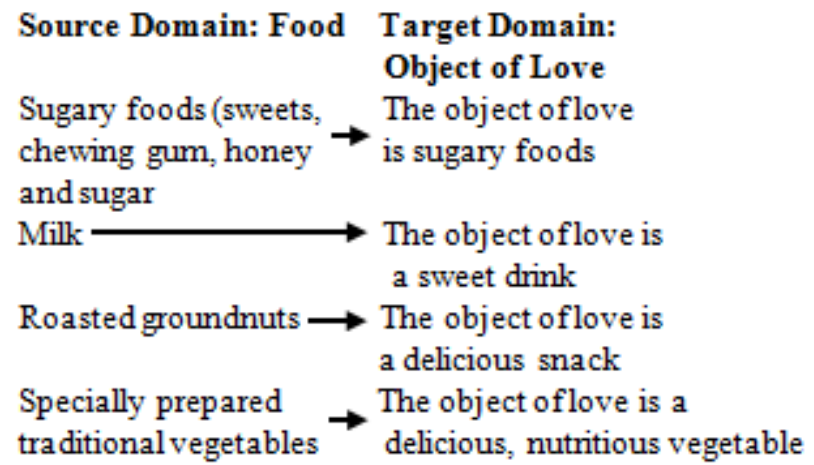

Figure 3. Cross domain mappings of OBJECT OF LOVE IS FOOD.

Objects of love are mapped onto tasty foods like the sugary foods which include sweets, chewing gum, honey and sugar. Other tasty foods are roasted ground nuts, specially prepared traditional vegetables and milk. From these mappings there are linguistic metaphors such as, bebi Patco ber nyodho (It feels good sucking my Patco), imiya herani duto an be amiyi duto hani (You give me all your love and I also give you mine my honey), Njugu karanga Adhiambo nya Alego (Adhiambo from Alego is roasted groundnuts), Maziwa yangu bebi (Baby you are my milk), Nikech hera maherigo sukarina (Because of the love I have for you my sugar), Adhiambo omboga mawendo, ithole, ikuoge iole chak (Adhiambo is foreign vegetable that is roasted, fermented, and added milk)and so on.

\section{Conclusions}

In conclusion, THE OBJECT OF LOVE IS FOOD conceptual metaphor has motivated numerous metaphoric expressions conceiving women as food confirming Damrosch's [10] definition of a metaphor as a figure of speech that describes one thing in terms of another. It is also worth pointing out that all the discussed metaphoric expressions of love contain locally available foods among the Luo (honey, sugar, sweets, milk, groundnuts and traditional vegetables) and this could explain their choice by the two Luo benga artistes. This present study therefore concludes that the specific conceptual metaphors derived from the generic conceptual metaphor THE OBJECT OF LOVE IS FOOD by the two Dholuo benga artistes include: WOMEN ARE HONEY, WOMEN ARE SUGAR, WOMEN ARE SWEETS, WOMEN ARE MILK, WOMEN ARE GROUNDNUTS and WOMEN ARE TASTY TRADITIONAL VEGETABLES. These choices of tasty foods can be contrasted with Kövecses [4]. Kövecses [4] stated that in English, men referred to women as tasty foods such as honey, sweets, cookies and sweetie pie. The choice of honey and sweets is shared by both Kövecses and the present study this could be because they are popular to both communities. Hines too examines WOMAN AS DESSERT conceptual metaphor which also views WOMEN AS HONEY, WOMEN AS CHEESECAKE, WOMEN AS TART and so on. These conceptual metaphors are a pointer to WOMEN ARE SWEET conceptual metaphor; similar to the findings of the present study. To sum up, Kandenge [11] points out that we use metaphorical expressions drawn from our environment to show cognitive view of language and we use existing cognitive models in the process of mapping from one cognitive domain to another. There exist similarities and variations in conceptualization of OBJECT OF LOVE IS FOOD between Ochieng Kabaselleh (1970s) and Atomi Sifa (2000s). Both artistes refer to their lovers as foods which they consider tasty. The two artistes have a shared perception of tasty foods which include sweets, honey, sugar and milk. Similarities have been attributed to the fact that metaphor is grounded to physical experience. This means the benga artistes have a shared cultural background. Regarding variations, for example, the differences in the specific linguistic terms used in reference to sweets (Patco and Big $G$ ) by Atomi Sifa (2000s) and Ochieng Kabaselleh (1970s) on the contrary uses a general term (sweet), has been attributed to individual difference in linguistic style (idiolect). This means the variation is on individual dimension brought about by Atomi's creative use of words. The similarities and variations in the conceptual metaphors aid in explaining the choice of words used by the two benga artistes in reference to their loved ones. It further offers insight into the use of language in Dholuo benga love songs. 


\section{REFERENCES}

[1] Kövecses, Z. (2002). Metaphor: A Practical Introduction. New York: Oxford University Press.

[2] Lakoff \& Johnson, M. (1980). Metaphors We Live By. Chicago: University of Chicago Press.

[3] Butler, C. (2005). The Dynamics of Language Use. Functional and Contrastive Perspectives. Amsterdam: John Benjamins.

[4] Kövecses, Z. (2003). Metaphor and Linguistic Expressions. In Kövecses, Z. (2005). Metaphor in Culture Universality and Variation. Cambridge: Cambridge University Press.

[5] Kövecses, Z. (2000). Metaphor and Emotion. New York and Cambridge: Cambridge University Press.

[6] Hines, C. (1994). Rebaking the Pie: The Woman as Dessert
Metaphor, in Bulchotz, A., Liang, C., and Sulton, L., (eds) Reinventing Identities: The Gendered Self in Discourse 145 - 162. Oxford: Oxford University Press.

[7] Daily Nation, Friday, March 25, 2011. How to Tell Your Benga from Rhumba.

[8] Deignan, A. (2005). Metaphor and Corpus Linguistics. Amsterdam: John Benjamins.

[9] Okumba, M. S. (2001). Oral Literature of the Luo People. Nairobi: East African Educational Publishers.

[10] Damrosch, L. (1985). Adventures in English Literature. San Diego: Harcourt Brace Jovanovich.

[11] Kadenge, M. (2010). Shona Metaphors Created During the Zimbabwean Crisis. A Cognitive Grammar Analysis. An Unpublished M.A. thesis. University of the Witwatersrand, Johannesburg, South Africa. 